\title{
Temporal Dynamics of Wheat Blast Epidemics and Disease Measurements Using Multispectral Imagery
}

\author{
C. Gongora-Canul, ${ }^{1}$ J. D. Salgado, ${ }^{2}$ D. Singh, ${ }^{3}$ A. P. Cruz, ${ }^{1}$ L. Cotrozzi, ${ }^{4}$ J. Couture, ${ }^{5}$ M. G. Rivadeneira, ${ }^{6}$ G. Cruppe, ${ }^{3}$ \\ B. Valent, ${ }^{3}$ T. Todd, ${ }^{3}$ J. Poland, ${ }^{3}$ and C. D. Cruz ${ }^{1, \dagger}$ \\ ${ }^{1}$ Department of Botany and Plant Pathology, Purdue University, West Lafayette, IN 47907, U.S.A. \\ 2 Department of Plant Pathology, The Ohio State University, Wooster, OH 44691, U.S.A. \\ ${ }^{3}$ Department of Plant Pathology, Kansas State University, Manhattan, KS 66506, U.S.A. \\ ${ }^{4}$ Department of Agriculture, Food and Environment, University of Pisa, Italy \\ 5 Departments of Entomology and Forestry and Natural Resources and Center for Plant Biology, Purdue University, 901 W. State St., West \\ Lafayette, IN 47907, U.S.A. \\ ${ }^{6}$ Centro de Investigación Agrícola Tropical, Estación Experimental Agrícola de Saavedra-EEAS, Santa Cruz, Bolivia \\ Accepted for publication 16 September 2019.
}

\begin{abstract}
Wheat blast is a devastating disease caused by the Triticum pathotype of Magnaporthe oryzae. M. oryzae Triticum is capable of infecting leaves and spikes of wheat. Although symptoms of wheat spike blast $\left(\mathrm{W}_{\mathrm{S}} \mathrm{B}\right)$ are quite distinct in the field, symptoms on leaves $\left(\mathrm{W}_{\mathrm{L}} \mathrm{B}\right)$ are rarely reported because they are usually inconspicuos. Two field experiments were conducted in Bolivia to characterize the change in $\mathrm{W}_{\mathrm{L}} \mathrm{B}$ and $\mathrm{W}_{\mathrm{S}} \mathrm{B}$ intensity over time and determine whether multispectral imagery can be used to accurately assess $\mathrm{W}_{\mathrm{S}} \mathrm{B}$. Disease progress curves (DPCs) were plotted from $\mathrm{W}_{\mathrm{L}} \mathrm{B}$ and $\mathrm{W}_{\mathrm{S}} \mathrm{B}$ data, and regression models were fitted to describe the nature of $\mathrm{W}_{\mathrm{S}} \mathrm{B}$ epidemics. $\mathrm{W}_{\mathrm{L}} \mathrm{B}$ incidence and severity changed over time; however, the mean $\mathrm{W}_{\mathrm{L}} \mathrm{B}$ severity was inconspicuous before wheat began spike emergence. Overall, both Gompertz and logistic models helped to describe $\mathrm{W}_{\mathrm{S}} \mathrm{B}$ intensity DPCs fitting classic sigmoidal shape curves. Lin's concordance correlation coefficients were estimated
\end{abstract}

ABSTRACT to measure agreement between visual estimates and digital measurements of $\mathrm{W}_{\mathrm{S}} \mathrm{B}$ intensity and to estimate accuracy and precision. Our findings suggest that the change of wheat blast intensity in a susceptible host population over time does not follow a pattern of a monocyclic epidemic. We have also demonstrated that $\mathrm{W}_{\mathrm{S}} \mathrm{B}$ severity can be quantified using a digital approach based on nongreen pixels. Quantification was precise $(0.96<r>0.83)$ and accurate $(0.92<\rho>0.69)$ at moderately low to high visual $\mathrm{W}_{\mathrm{S}} \mathrm{B}$ severity levels. Additional sensor-based methods must be explored to determine their potential for detection of $\mathrm{W}_{\mathrm{L}} \mathrm{B}$ and $\mathrm{W}_{\mathrm{S}} \mathrm{B}$ at earlier stages.

Keywords: disease control and pest management, ecology and epidemiology, etiology, mycology, phenotyping, plant disease, remote sensing, techniques, wheat blast
Wheat blast (WB) is a fungal disease that can cause total losses to wheat producers during outbreak years. The causal agent, Magnaporthe oryzae pathotype Triticum was reported for the first time in wheat in Brazil (Igarashi et al. 1986) and is now present in other countries in South America (Barea and Toledo 1996; Cabrera and Gutiérrez 2007; Viedma 2005) and South Asia (Malaker et al. 2016). Limited ecological and epidemiological information on M. oryzae Triticum makes the WB disease hard to contain and control, and recommendations about the deployment of crop protection tactics such as fungicide applications remain a challenge (Cruz et al. 2015, 2019). Under such a scenario, growers tend to use fungicide spray schedules without knowing whether or not they are necessary. They are unable to estimate the economic cost/benefit but apply treatment with the hope to ensure crop success (Cruz and Valent 2017; Cruz et al. 2019; Devanna and Sharma 2017). For instance, in areas where WB is endemic in Brazil and Bolivia,

†Corresponding author: C. D. Cruz; cd-cruz@purdue.edu

Funding: Purdue University start-up funds, Agriculture and Food Research Initiative Competitive Grant number 2013-68004-20378 from the United States Department of Agriculture-National Institute of Food and Agriculture, and International Wheat Yield Partnership Grant number 2017-67007-25933 (project accession number 1011391).

*The $\boldsymbol{e}$-Xtra logo stands for "electronic extra" and indicates that two supplementary figures and two supplementary tables are published online.

The author(s) declare no conflict of interest.

(C) 2020 The American Phytopathological Society producers rely on many fungicide applications (i.e., three or more) as a last resort to control the disease (Cruz and Valent 2017; Cruz et al. 2019). To date, the monocyclic or polycyclic nature of WB epidemics is subject to debate, and the epidemiological importance of leaf blast for spike blast development is mostly unknown (Cruz and Valent 2017; Cruz et al. 2015, 2019). M. oryzae Triticum is capable of infecting leaves and spikes of wheat (Cruz and Valent 2017; Cruz et al. 2016b; Gomes et al. 2019; Igarashi et al. 1986). Although symptoms of spike blast $\left(\mathrm{W}_{\mathrm{S}} \mathrm{B}\right)$ are quite distinct in the field, symptoms on leaves $\left(\mathrm{W}_{\mathrm{L}} \mathrm{B}\right)$ are rarely reported because they are usually less noticeable. Therefore, temporal analysis of $\mathrm{W}_{\mathrm{L}} \mathrm{B}$ and $\mathrm{W}_{\mathrm{S}} \mathrm{B}$ are necessary to better characterize epidemics caused by M. oryzae Triticum and to develop better WB management strategies.

Trained human experts perform traditional blast disease surveillance using qualitative and quantitative rating scales (Bock et al. 2010; Madden et al. 2007) yet the need to cover a large number of plants while surveying at a fine resolution is a challenge. In the last 40 years, innovative methods continue to be explored to quantify plant disease, which include methods of detecting and measuring disease at the plant population level (Bock et al. 2010; Dash et al. 2017; Mahlein 2016; West et al. 2003; Zhang and Kovacs 2012). Commercial autonomous aerial systems (also known as unmanned aerial vehicles [UAVs] or drones) offer an alternative for plant disease phenotyping because they can be equipped with a wide range of electronic sensors (Dash et al. 2017; Mahlein 2016; West et al. 2003; Zhang and Kovacs 2012). A significant benefit of UAVs is that they allow for phenotyping at relatively larger plant population 
scales (Zhang and Kovacs 2012). Automated, sensor-based methods have the potential to improve detection and quantification of disease symptoms and to provide a tool to maximize the efficiency of surveillance and crop protection strategies (Bock and Nutter 2011; Mohanty et al. 2016). Previous research in crop physiology and, to a lesser extent, plant pathology have shown evidence that many plant attributes can be estimated using sensor-based techniques (Albetis et al. 2017; Calderón et al. 2014; Heim et al. 2019; Mahlein 2016; Zarco-Tejada et al. 2018). These sensors collect information on the optical characteristics of plants within various ranges of the electromagnetic spectrum (Mahlein 2016). Plant pathogens can produce physiological and structural modifications at the individual plant or organ level and, therefore, sensors can enable the detection of these changes (West et al. 2010). Sensors that measure spectral reflectance, temperature, or fluorescence are the most promising for plant pathology applications (Mahlein 2016). A few studies have used multispectral sensors for plant disease symptom assessment (Albetis et al. 2017; Calderón et al. 2014; Heim et al. 2019; Mahlein 2016). However, no previous study has evaluated agreement (precision and accuracy) between visual estimates of disease symptoms and digital measurements on a temporal basis.

Current goals in plant phenotyping include raising the quality of plant disease assessments and throughput of phenotype inference while decreasing costs through automation and data integration (Bock et al. 2010; Rahaman et al. 2015). However, measurement devices can incorrectly assess disease symptoms, and this can lead to error (Nita et al. 2003; Nutter and Litwiller 1993; Nutter et al. 2006). Reliability (precision) and accuracy (Barnhart et al. 2007) suggest a standard of quality of plant disease assessments (Bock et al. 2010; Madden et al. 2007; Rahaman et al. 2015). Although standard statistical tests have been established, the precision and accuracy of quantitative disease estimations are often not confirmed (Campbell and Madden 1990; Madden et al. 2007; Nutter and Schultz 1995; Nutter et al. 2006). Reliable and accurate estimations of plant disease signs and symptoms are essential for monitoring and forecasting epidemics, evaluating crop germplasm for disease resistance, developing effective disease management programs, and predicting yield loss (Guan and Nutter 2001, 2004; Madden et al. 2007; Nutter et al. 2006). Precision is the degree to which the same measurements of diseased specimens obtained under different conditions yield similar results (Everitt and Skrondal 2010). Accuracy is the degree of conformity to some recognized standard value (Everitt and Skrondal 2010). Due to the advent of electronic sensor-based techniques for disease quantification, further studies on the precision and accuracy of electronic sensor-based measurement of disease are needed (Bock et al. 2010). The most visible symptom of WB is bleaching of the spike, making this disease a good candidate for field-based phenotyping using UAVs and multispectral imagery. Following phytopathometry terminology (Bock et al. 2010), we use the term plant disease intensity "estimate" for assessments made visually and the term "measurement" for assessments by image analysis.

The objectives of this study were to (i) characterize the temporal development of $\mathrm{W}_{\mathrm{L}} \mathrm{B}$ and $\mathrm{W}_{\mathrm{S}} \mathrm{B}$ using traditional visual estimations and (ii) assess the agreement between multispectral remotely sensed data measurements and visual estimations of $W_{S} B$ symptoms under field conditions.

\section{MATERIALS AND METHODS}

Experiment layout. Experiments were carried out in two locations in Bolivia, the first at the Bolivian Oilseed and Wheat Growers Association Research Station CEA-2 located in Nuflo de Chavez Province, and the second at the CE-CAICO Agricultural
Cooperative research station located in Warnes Province. Experiments were planted on 24 and 25 April 2017, respectively, with certified seed of the blast-susceptible cultivar Atlax at 70 to 80 seeds per linear meter and at a depth of 2 to $3 \mathrm{~cm}$ in a conventional tillage system with $20-\mathrm{cm}$ row spacing and overall plot dimensions of 3 by $2 \mathrm{~m}$ at CEA- 2 and 4 by $3 \mathrm{~m}$ at CE-CAICO. Seed was treated with carbendazim + thiram at a rate of $150 \mathrm{ml}$ per $100 \mathrm{~kg}$ of seed (Toledo 2015).

The experiment was established as a randomized complete block design with eight replications as blocks factors, and two treatments (M. oryzae Triticum inoculated and noninoculated plots) randomly assigned into blocks. In an effort to minimize interplot interference, plots were separated by $1-\mathrm{m}$ border rows of corn. No foliar fungicides were used in this experiment. Herbicides and insecticides were used for postemergent management of weeds and pests and both locations relied heavily on supplemental irrigation. The main reason is that experiments were conducted during a nonoutbreak year for WB in Bolivia, following a record drought that drained lakes and farmlands (ReliefWeb 2017; Weiss 2018). Supplemental irrigation favored unique conditions for the development of WB symptoms on leaves and spikes during that year. Prior to inoculation, no blast symptoms were observed in nearby wheat fields.

Inoculation. $M$. oryzae Triticum conidia were produced at the Bolivian Research Center for Tropical Agriculture (CIAT). Cultures were grown on homemade oatmeal agar (Valent et al. 1991) consisting of $50 \mathrm{~g}$ of rolled oat in $500 \mathrm{ml}$ of water heated at $70^{\circ} \mathrm{C}$ for $1 \mathrm{~h}$, then filtered through four layers of cheese cloth, adjusted to 1 liter with $1.5 \%$ agar added, and autoclaved. Agar plates were incubated at 23 to $25^{\circ} \mathrm{C}$ under continuous fluorescent illumination $\left(25 \mu \mathrm{mol} \mathrm{m} \mathrm{m}^{-2} \mathrm{~s}^{-1}\right)$. Colonies of 5 to 7 days in age were flooded with sterile deionized water containing $0.42 \%$ (wt/wt) gelatin and $0.01 \%$ (vol/vol) Tween-20 (Sigma-Aldrich) surfactant and gently scraped with an inoculation loop to dislodge conidia from conidiophores. Inoculation was done late in the evening on 26 May 2017 (CEA-2) and 27 May 2017 (CE-CAICO) when wheat was at the Feekes growth stage 1 (i.e., three leaves unfolded). The M. oryzae Triticum conidial suspension was adjusted to $24.6 \times 10^{3}$

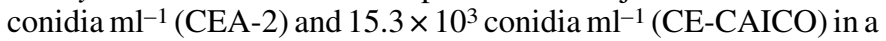
solution of deionized water, gelatin, and Tween-20 and applied with a dedicated backpack sprayer to corresponding experimental units (i.e., inoculated plots). Directly following inoculation, each inoculated plot was covered with a polyethylene tarp during a 48-h period.

Visual disease estimation. Plant disease estimates (Bock et al. 2010) were used to study the temporal dynamics of $W_{L} B$ and $W_{S} B$ disease intensity (i.e., severity and incidence). Individual leaves of 25 to 50 plants per plot were assessed for $\mathrm{W}_{\mathrm{L}} \mathrm{B}$ symptoms prior to and after inoculation at each rating time during the wheat vegetative stages. During the reproductive stages, 100 spikes per plot were assessed for disease at each assessment time. Severity was assessed as percent disease area within individual leaves or spikes (Cruz et al. 2012). For spikes, severity was estimated as the proportion of diseased spikelets of the total number of spikelets on a given spike: $\mathrm{W}_{\mathrm{S}} \mathrm{B}_{\text {sev }}=$ (number of diseased spikelets/total spikelets) $\times 100$ (Cruz et al. 2012). Incidence consisted of the number of plants or spikes that showed $\mathrm{W}_{\mathrm{L}} \mathrm{B}$ or $\mathrm{W}_{\mathrm{S}} \mathrm{B}$ symptoms, relative to the total number of plants or spikes assessed, on an individual basis. Three raters performed $\mathrm{W}_{\mathrm{L}} \mathrm{B}$ and $\mathrm{W}_{\mathrm{S}} \mathrm{B}$ visual disease estimations. Precision of visual disease estimation was high $\left(R^{2}>80 \%\right)$ according to intraand interrater assessments made with Severity. Pro (Nutter et al. 2006) and with comparisons against an experienced evaluator, respectively. Visual severity and incidence data were taken at six timepoints for $\mathrm{W}_{\mathrm{L}} \mathrm{B}$ (between 0 and 35 days after inoculation [DAI]) and eight time points for $\mathrm{W}_{\mathrm{S}} \mathrm{B}$ (between 35 and $62 \mathrm{DAI}$ ) at each location. Disease progress curves were plotted based on $\mathrm{W}_{\mathrm{L}} \mathrm{B}$ and $\mathrm{W}_{\mathrm{S}} \mathrm{B}$ raw data; further analyses were performed only from the data collected on spikes. 
The area under the disease progress curve (AUDPC) was calculated for $\mathrm{W}_{\mathrm{S}} \mathrm{B}$ severity and incidence for both locations by using the trapezoidal integration method (Campbell and Madden 1990) to quantify disease progress. Analysis of variance (ANOVA) was performed using the PROC MIXED procedure in SAS (SAS Institute, Cary, NC, U.S.A.) on AUDPC values of $\mathrm{W}_{\mathrm{S}} \mathrm{B}$ visual severity and incidence for inoculated and noninoculated plots.

Graphical (observed $y$ versus $t$ or transformed $y^{*}$ versus $t$ ) and statistical approaches were used to characterize the temporal dynamic of visual $\mathrm{W}_{\mathrm{S}} \mathrm{B}$ incidence and severity over time (Campbell and Madden 1990). The independent variable was DAI and the dependent was either $\mathrm{W}_{\mathrm{S}} \mathrm{B}$ incidence or severity. Four population growth models (Campbell and Madden 1990; Madden et al. 2007) were fitted in their linearized form to describe $\mathrm{W}_{\mathrm{S}} \mathrm{B}$ epidemics. Linear transformations of models were useful because it was easier to visualize the effects of changes of initial disease $\left(y_{0}\right)$ and rate of disease progression $(r)$ with straight lines than with curves (Bowen 2015; Campbell and Madden 1990; Madden et al. 2007).

Ordinary least squares regression was performed with SAS for each possible model (Campbell and Madden 1990; Madden et al. 2007). The goodness-of-fit models to describe each epidemic were assessed by comparing the observed and transformed disease progress curves (DPCs), examining the coefficients of determination $\left(R^{2}\right)$, mean square error (RMSE), and the plots of residual errors versus predicted values (Campbell and Madden 1990). Final selection and comparison of models to describe $\mathrm{W}_{\mathrm{S}} \mathrm{B}$ epidemics was based on the Akaike's Information Criterion (AIC) (RennerMartin et al. 2016), and performed using SAS PROC REG/ SELECTION. In addition, linear mixed-model analysis of slopes and intercepts, with fixed inoculation effects and random block effects, was performed using SAS PROC MIXED for the model that best described $\mathrm{W}_{\mathrm{S}} \mathrm{B}$ epidemics.

Digital imagery disease measurement. Raw multispectral images were taken with a RedEdge-M multispectral camera (Micasense, Inc., Seattle, WA, U.S.A.), mounted on a Matrice100 UAV (SZ DJI Technology Co., Ltd., Shenzhen, China). The spectral bands of the multispectral camera (narrowband) included blue, green, red, red edge, and near-infrared. The center wavelengths for each corresponding band were 475, 560, 668, 717, and $840 \mathrm{~nm}$. Following Singh et al. (2019), the mission waypoints were established with the Litchi autonomous flight app (VC Technology Ltd., London, U.K.) and the UAV flight was set at an altitude of $15 \mathrm{~m}$ above ground level. The UAV was piloted at midday at $2 \mathrm{~m} / \mathrm{s}$ in clear-sky conditions, and covered an area 0.1 ha larger than the experimental area to obtain proper orthomosaics. The camera acquired images with $85 \%$ lateral and longitudinal overlaps, and the ground resolution was $1 \mathrm{~cm} /$ pixel. Digital images were taken at five $(43,47,55,57$, and $60 \mathrm{DAI})$ and three $(45,55$, and $58 \mathrm{DAI})$ different time points during heading at the CEA-2 and the CE-CAICO research stations, respectively (Supplementary Fig. S1). Images of an approved calibration reflectance panel (CRP) with known reflectance properties developed by the manufacturer were collected prior to each flight. To facilitate the temporal analysis of UAV imagery, images of the CRP were used to perform radiometric calibrations of the raw images at each time-point using the Micasense Atlas cloud image-processing pipeline (https://atlas. micasense.com/app/login). The pipeline used original flight metadata (gain, exposure, and position) and calibration panel images to convert each individual raw pixel into a reflectance value (https:// github.com/micasense/imageprocessing). It did so by performing a series of pixel-level operations, including dark pixel offset, exposure and gain normalization, and imager-level and optical chain effect compensation. Spectral signatures from imagery were evaluated to verify conformity (Supplementary Fig. S1). The final end product of this workflow was the radiometrically calibrated five-band orthomosaic images. The final orthomosaic images were downloaded and subsequent image operations were performed on a local computer.
Digital crop cover was estimated via supervised classification procedure on the orthomosaic raster image. Image pixels were classified as belonging to each soil, green vegetation, and shadow class by a semiautomatic classification (SCP) plugin within QGIS 2.2 (Congedo 2016; QGIS Development Team 2017). Subsequent to image classification, the plot-level cover was extracted using custom $\mathrm{R}$ functions. The functions used classified image outputs from the SCP plugin and a plot boundary shapefile as inputs to extract the plot-level digital crop cover as the proportion of green vegetation pixels (gvp) falling under the plot boundary shapefile. The gvp classification accuracy was tested by randomly creating regions of interest (ROI), using an ROI option within the SCP plugin in QGIS, from selected flight dates at each location. Each ROI was manually labeled for the class of each of the categorical classes (i.e., vegetation, shadow, and soil). The classification accuracy of each class was subsequently calculated based on the observed and predicted pixel classes. The overall accuracy was 89 to $94 \%$ at CECAICO and 74 to $97 \%$ for CEA-2. Data distributions from each time point were plotted and outliers corresponding to plots with poor vegetation coverage were removed. After image classification, the plot-level proportion of nongreen vegetation pixels (1-gvp) was used as a proxy of $\mathrm{W}_{\mathrm{S}} \mathrm{B}$ digital scores. Values were later expressed as percentage for analysis purposes. Additionally, we extracted vegetative indices (VIs) eligible for the multispectral data collected. VIs represent products of remote sensing based on transformations of spectral bands of the electromagnetic spectrum measured as reflectance (Mahlein et al. 2013). VIs used in this study included the normalized difference VI (Rouse et al. 1974), normalized difference red edge (NDRE) (Barnes et al. 2000), green normalized difference VI (Gitelson and Merzlyak 1998), green ratio VI (GRVI) (Sripada et al. 2006), and optimized soil-adjusted VI (OSAVI) (Rondeaux et al. 1996). Normalization is effective at canceling atmospheric disturbance or other error sources as well as enhancing and standardizing the spectral response to observed targets (Couture et al. 2018; Inoue et al. 2008).

Agreement between $W_{S} B$ estimates and measurements. Analyses of assessment data were performed based on the ability of the disease measurement device compared with the "actual" value of disease (Bock et al. 2010; Madden et al. 2007; Nutter et al. 1991). These analyses adhere to those statistical methods described by Madden et al. (2007) and reflect the most recent developments in phytopathometry (Bock et al. 2010). Visual estimation of $\mathrm{W}_{\mathrm{S}} \mathrm{B}$ symptoms was used as ground truth by means of in-situ observations to measure agreement with digital $\mathrm{W}_{\mathrm{S}} \mathrm{B}$ measurements (i.e., proportion of nongreen vegetation pixels and widely used VIs). Accuracy, precision and bias of digital disease measurements (Madden et al. 2007; Nutter et al. 1991) were evaluated. Accuracy is a product of precision and bias (Madden et al. 2007; Nita et al. 2003). Accuracy was calculated with Lin's concordance correlation coefficient $\left(\rho_{c}\right)$ which measures the variation of data from a concordance line, a 1:1 line with an intercept of zero and a slope of one (Bock et al. 2010; Lin 1989; Nita et al. 2003). To obtain $\rho_{c}$, we used the equation $\rho_{c}=r \times C_{b}$, where the correlation coefficient $r$ was a measure of precision (i.e., scatter points around the best fitting line; $r=1$ for a perfectly straight line), and $C_{b}$ a measure of bias (i.e., the closeness of the best fitting line to the concordance line; $C_{b}=1$ in the absence of bias). $C_{b}$ was calculated with the equation $C_{b}=2 /$ $\left[u^{2}+v+(1 / v)\right]$, where $v=\left(\sigma_{1} / \sigma_{2}\right)$ indicated scale shift or difference in slope of the concordance and best-fit lines ( $v=1$ for equal slopes), and $u=\left[\left(\mu_{1}-\mu_{2}\right) / \sqrt{ }\left(\sigma_{1} \times \sigma_{2}\right)\right]$ indicated location shift or height differences in the concordance and best-fitting lines ( $u=0$ for equal intercepts), and where $\mu_{1}$ and $\mu_{2}$ are means of measured values (digital disease measurement) and true values (visual disease estimates), and $\sigma_{1}$ and $\sigma_{2}$ are their standard deviations calculated based on maximum-likelihood estimates (Madden et al. 2007; Nita et al. 2003).

A regression analysis was performed, followed by Lin's concordance analysis. Estimation of accuracy, precision, and 
bias of digital disease estimation were performed using PROG REG ALL procedure on SAS, according to a macro statement developed by Lawrence Lin and verified by Min Yang (Lin et al. 2002).

\section{RESULTS}

Wheat blast developed in both field locations and symptoms were observed on leaves and spikes. Inoculated plots had higher $\mathrm{W}_{\mathrm{L}} \mathrm{B}$ and $\mathrm{W}_{\mathrm{S}} \mathrm{B}$ intensity than non-inoculated plots and results were consistent at both CEA-2 and CE-CAICO locations. There was no evidence of interplot interference and there was a significant effect of $M$. oryzae Triticum inoculum on the onset of epidemics (Table 1). Interestingly, $\mathrm{W}_{\mathrm{L}} \mathrm{B}$ symptoms were observed throughout the canopy with $\mathrm{W}_{\mathrm{L}} \mathrm{B}$ incidence values being higher on inoculated plots compared with noninoculated plots. $\mathrm{W}_{\mathrm{L}} \mathrm{B}$ incidence and severity changed over time (Fig. 1). However, mean $\mathrm{W}_{\mathrm{L}} \mathrm{B}$ severity was inconspicuous and remained below $3 \%$ on inoculated and $0.2 \%$ on noninoculated plots at both locations before wheat began spike emergence (Fig. 1B and D). Although the focus of this study was $\mathrm{W}_{\mathrm{S}} \mathrm{B}$, the fact that leaf blast symptoms were observed in all inoculated plots was evidence that $\mathrm{W}_{\mathrm{L}} \mathrm{B}$ lesions played a role on the onset of the $\mathrm{W}_{\mathrm{S}} \mathrm{B}$ development and epidemics. $\mathrm{W}_{\mathrm{S}} \mathrm{B}$ disease incidence and severity were higher in MoT inoculated plots than in noninoculated plots (Fig. 2). ANOVA indicated significant effects $(P<0.01)$ of the MoT inoculation treatment on the AUDPC of $\mathrm{W}_{\mathrm{S}} \mathrm{B}$ incidence and severity at both locations (Table 1). DPCs of inoculated plots showed a continuous progress of $\mathrm{W}_{\mathrm{S}} \mathrm{B}$ symptoms from near zero to maximum intensity in a period of 17 days at the CE-CAICO and 22 days at the CEA-2 location. Higher levels of $\mathrm{W}_{\mathrm{S}} \mathrm{B}$ symptoms were observed at the CE-CAICO location than at the CEA-2 location (Fig. 2).

Ordinary least squares regression was performed for each possible population growth model and values of $R^{2}, \mathrm{RMSE}$, and residuals were compared. The exponential and monomolecular models (Supplementary Tables S1 and S2) were deemed inadequate based on the criteria for model selection, including the transformation of $y\left(y^{*}\right)$ plotted versus $t$, which did not show adequate linear fit (Fig. 3). The Gompertz model showed the best linear fit to the data (Fig. 3) for incidence and severity at both locations, as suggested by analysis of linear parameters and test of residuals.

At the CEA-2 location, the Gompertz model overall resulted in the highest $R^{2}$ (0.94 to 0.98$)$ and the lowest RMSE (0.16 to 0.35 ) across treatments and $\mathrm{W}_{\mathrm{S}} \mathrm{B}$ intensity. Additionally, residuals for the Gompertz model appeared to have a random scatter about the fitted line, which is a strong indicator of an appropriate model

\section{C}
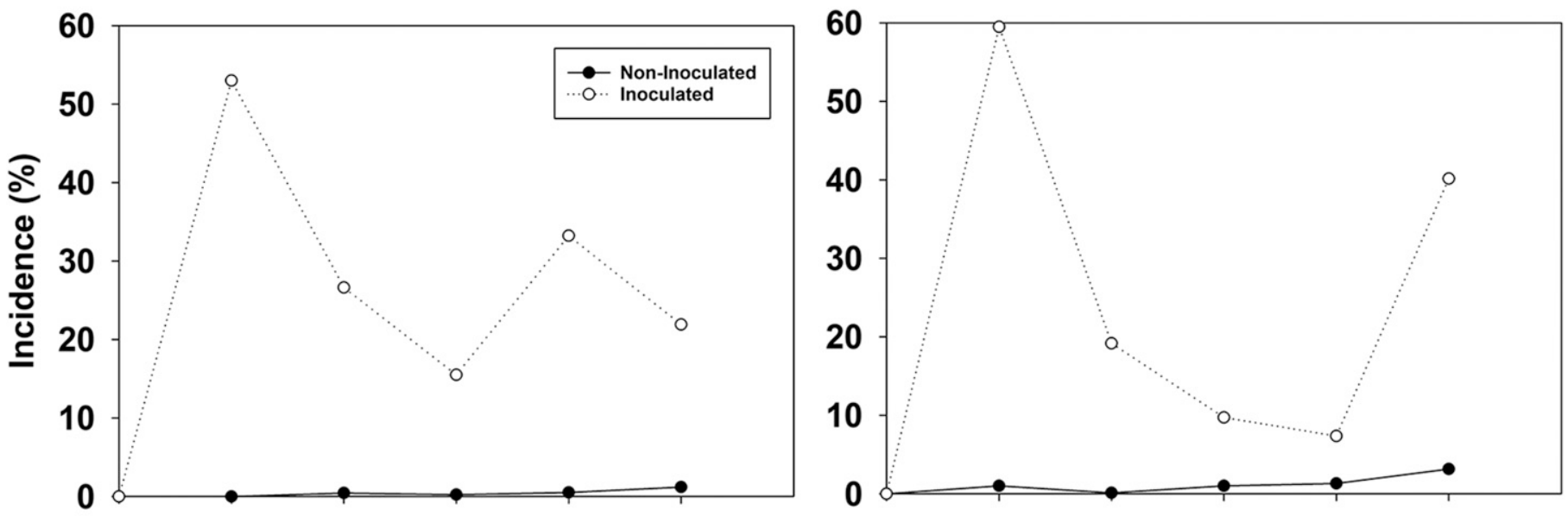

B
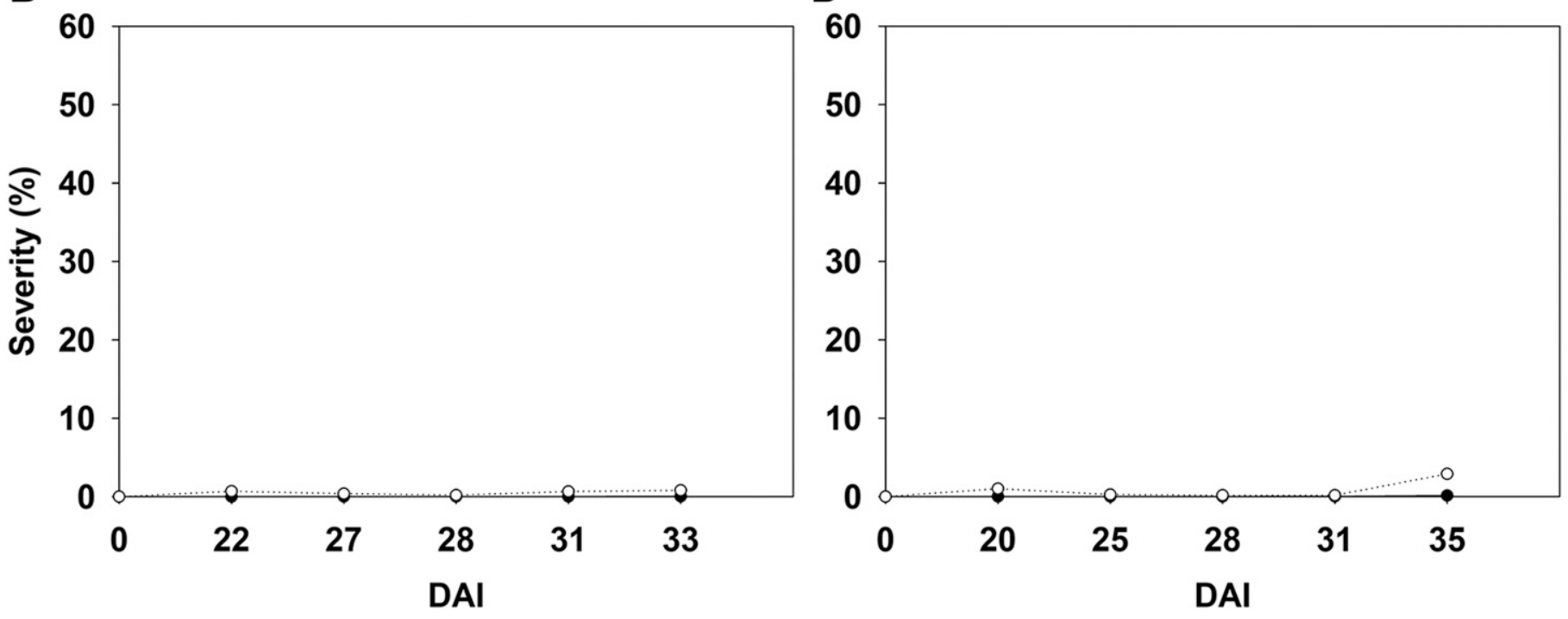

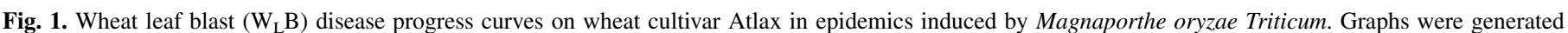

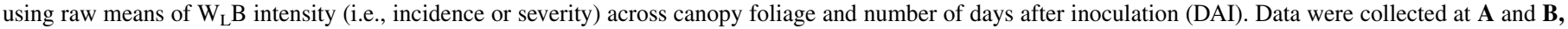
the CEA-2 location and $\mathbf{C}$ and $\mathbf{D}$, the CE-CAICO location in Bolivia in 2017. 
(Supplementary Table S1). For noninoculated plots at the CE-CAICO location, the Gompertz model resulted in the highest $R^{2}(0.96$ to 0.98 ) and the lowest RMSE (0.20 to 0.21$)$. It also provided adequate residual plots on noninoculated plots when $\mathrm{W}_{\mathrm{S}} \mathrm{B}$ intensity data were analyzed. For inoculated plots at the CE-CAICO location, both the logistic and Gompertz models were appropriate when $\mathrm{W}_{\mathrm{S}} \mathrm{B}$ incidence data were analyzed. Although the logistic model had the highest $R^{2}$ (0.86), Gompertz had the lowest RMSE (1.99). $\mathrm{W}_{\mathrm{S}} \mathrm{B}$ severity data from inoculated plots at the CE-CAICO location showed that the logistic model was appropriate based on its highest $R^{2}$ (0.84), lowest RMSE (2.18), and random scatter of residuals about the fitted line. However, the Gompertz model had the lowest
AIC on every single epidemic at both locations, based on severity and incidence data (Table 2).

When linear mixed-model analysis was performed using full datasets for the model that best described $\mathrm{W}_{\mathrm{S}} \mathrm{B}$ epidemics (i.e., Gompertz), results showed that intercepts (inoculation treatment) and slopes (DAI $\times$ inoculation treatment interaction) were nonequal when inoculation treatments were compared (Table 3). Epidemic development in M. oryzae Triticum-inoculated and noninoculated plots were different in terms of their estimated rate parameters, with consistently higher incidence and severity $r_{\mathrm{G}}$ $($ DAI $\times$ inoculation) estimates observed for inoculated plots at both locations (Table 4).
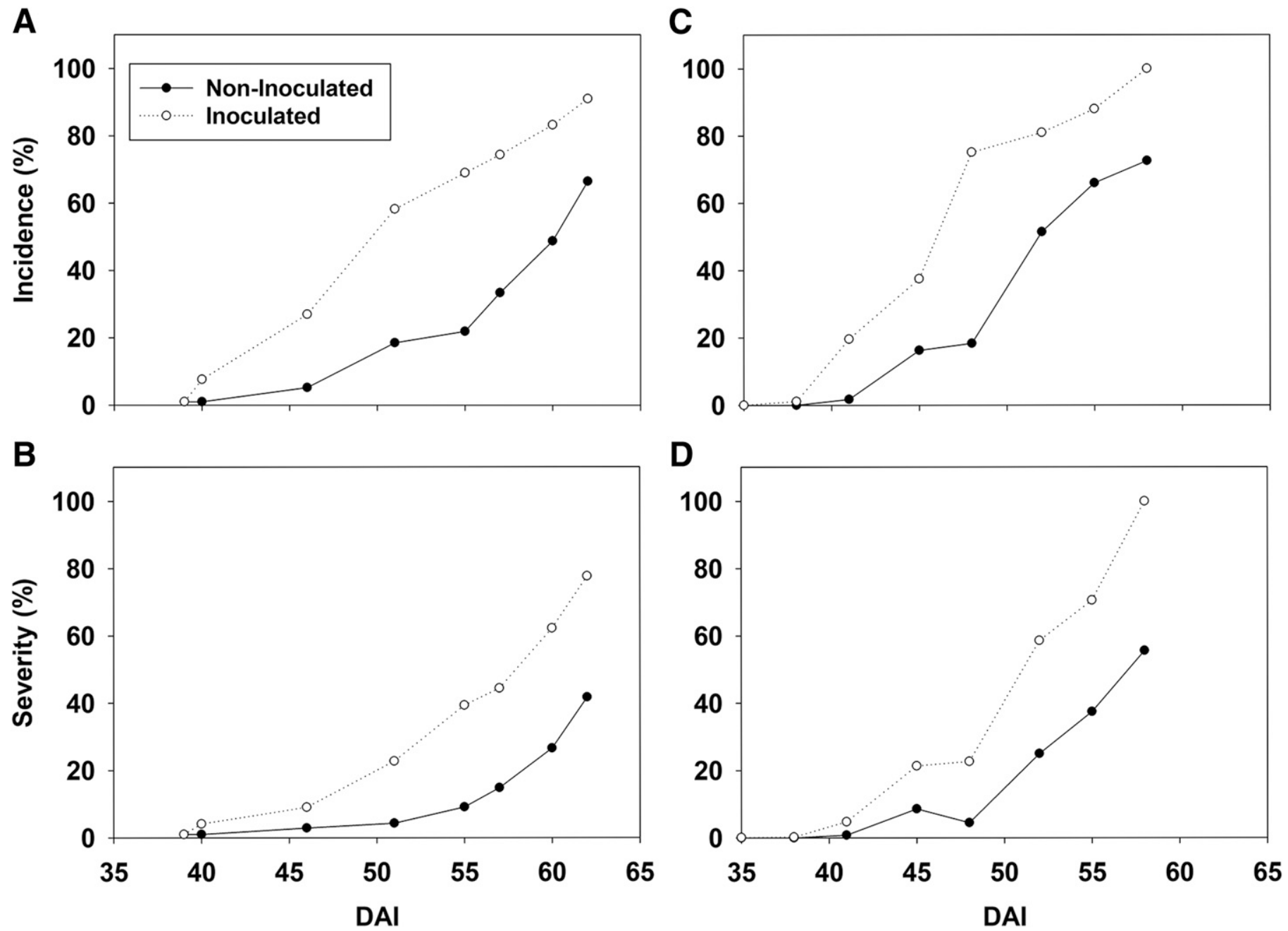

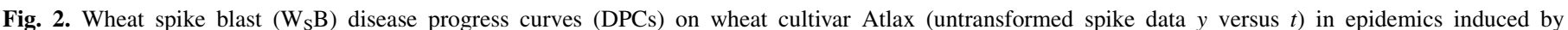

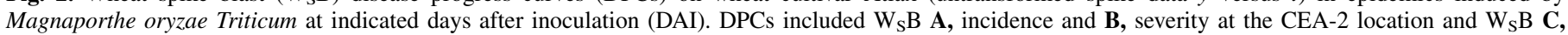
incidence and D, severity at the CE-CAICO location in Bolivia in 2017.

TABLE 1. Analysis of variance on the effect of Magnaporthe oryzae Triticum inoculation treatment on the area under the disease progress curve (AUDPC) of visual wheat spike blast $\left(\mathrm{W}_{\mathrm{S}} \mathrm{B}\right)$ severity and incidence ${ }^{\mathrm{a}}$

\begin{tabular}{|c|c|c|c|c|c|c|c|c|c|c|}
\hline \multirow{3}{*}{ Source $^{b}$} & \multicolumn{10}{|c|}{ AUDPC } \\
\hline & \multicolumn{5}{|c|}{ CEA-2 } & \multicolumn{5}{|c|}{ CE-CAICO } \\
\hline & \multicolumn{3}{|c|}{ Severity } & \multicolumn{2}{|c|}{ Incidence } & \multicolumn{3}{|c|}{ Severity } & \multicolumn{2}{|c|}{ Incidence } \\
\hline Treatment & 1 & 28.39 & 0.0011 & 28.39 & 0.0011 & 1 & 26.69 & 0.0010 & 28.65 & 0.0011 \\
\hline Block & 7 & 2.35 & 0.1413 & 2.35 & 0.1413 & 7 & 2.92 & 0.0902 & 2.49 & 0.1261 \\
\hline
\end{tabular}

${ }^{a}$ Locations included the CEA-2 and CE-CAICO in Bolivia in 2017.

b Source of variation. 

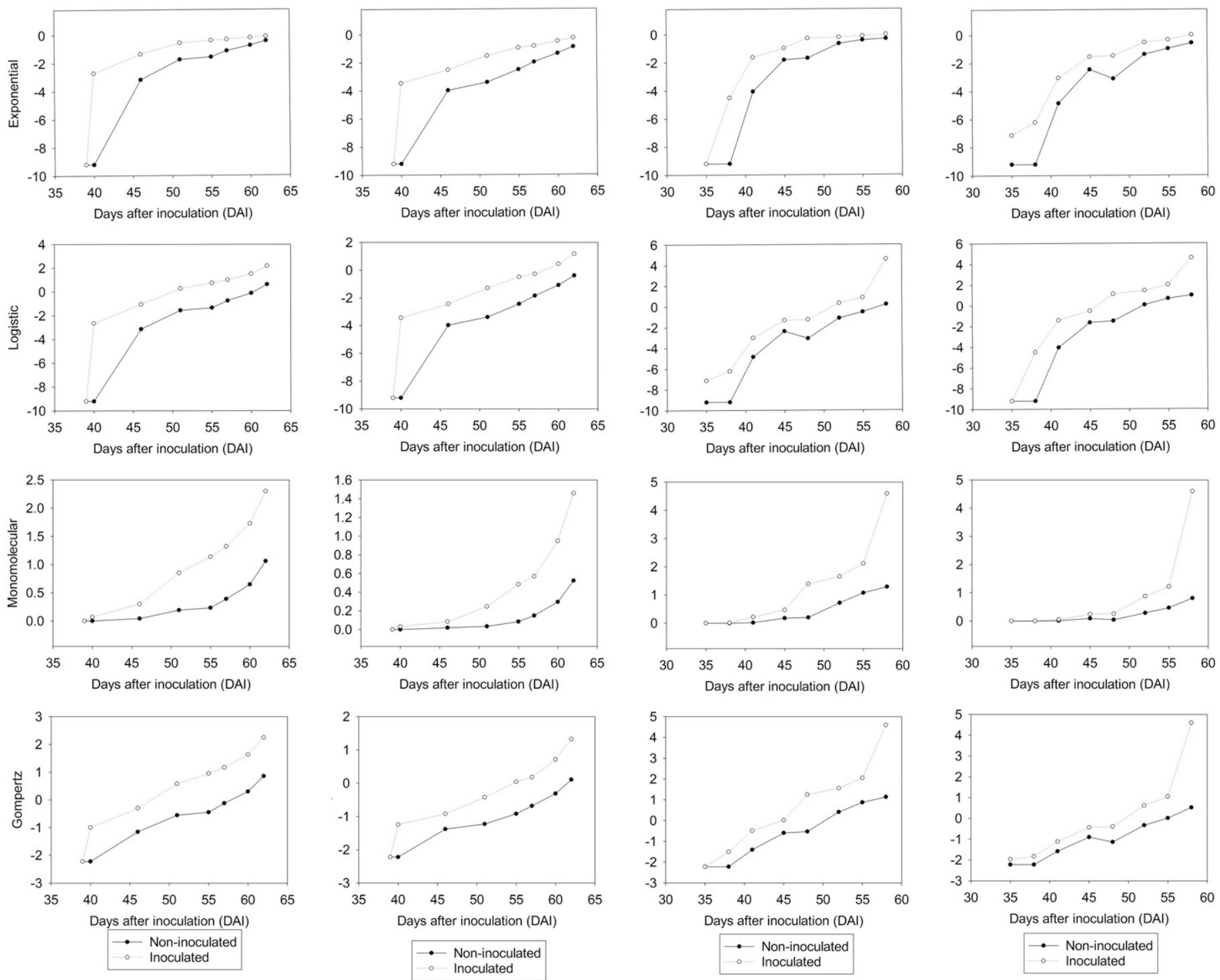

Fig. 3. Disease progress curves (DPCs) on wheat cultivar Atlax (transformed data $y^{*}$ versus $t$ ). DPCs included transformed wheat spike blast incidence and severity; data were collected at the CEA-2 and CE-CAICO locations in Bolivia in 2017.

TABLE 2. Comparison of models to describe wheat spike blast $\left(\mathrm{W}_{\mathrm{S}} \mathrm{B}\right)$ epidemics based on the Akaike's Information Criterion (AIC) ${ }^{\mathrm{a}}$

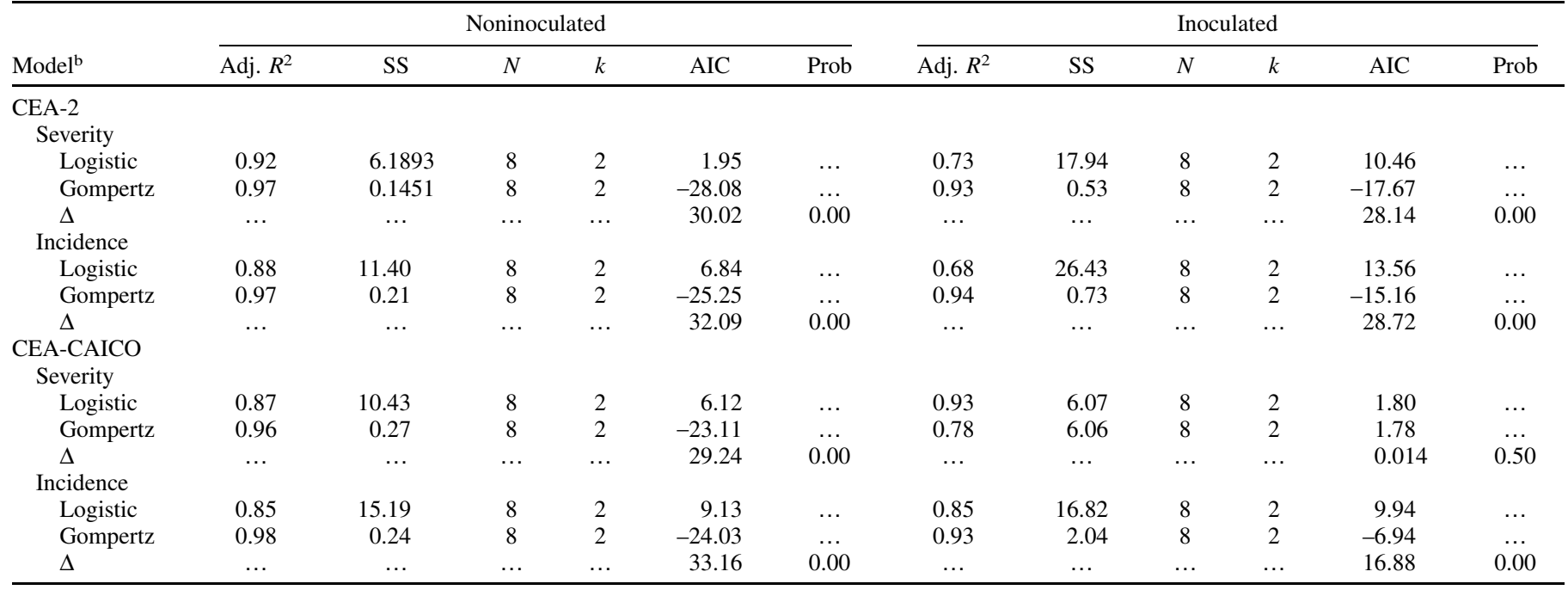

${ }^{a}$ Disease severity and incidence data were collected in 2017 at two locations in Bolivia: CEA-2 and CE-CAICO.

${ }^{\mathrm{b}}$ Location, $\mathrm{W}_{\mathrm{S}} \mathrm{B}$ intensity, and model. 
The VIs used in this study, in general, showed relatively high levels of precision at multiple time points when compared with incidence and severity estimates (Tables 5 and 6). However, their accuracy values were particularly low at both locations, except for NDRE at 47 DAI, GRVI at 55 DAI, and OSAVI at 43 and 47 DAI at the CEA-2 location, when comparisons where made against visual severity (Table 5).

The 1-gvp class allowed digital measurement of $\mathrm{W}_{\mathrm{S}} \mathrm{B}$ incidence and severity at different times during heading at both locations (Tables 5 and 6; Figs. 4 and 5). These times covered a range of $\mathrm{W}_{\mathrm{S}} \mathrm{B}$ development, from low to high visual disease intensity (Figs. 2, 4, and 5). For the CEA-2 location (Fig. 4), 1-gvp $\mathrm{W}_{\mathrm{S}} \mathrm{B}$ digital measurements compared with visual $\mathrm{W}_{\mathrm{S}} \mathrm{B}$ severity showed values of precision $(r) 0.31$ to 0.96 , accuracy $(\rho) 0.17$ to 0.92 , bias $\left(C_{b}\right) 0.53$ to 0.96 , scale shift $(v) 0.30$ to 1.4 , and location shift $(u) 0.1$ to 0.85 . For digital $\mathrm{W}_{\mathrm{S}} \mathrm{B}$ compared with visual $\mathrm{W}_{\mathrm{S}} \mathrm{B}$ incidence, $r$ ranged from 0.31 to $0.94, \rho$ from 0.09 to $0.91, C_{b}$ from 0.20 to $0.99, v$ from 0.16 to 1.40 , and $u$ from 0.1 to 1.98 . For the CE-CAICO location (Fig. 5), $\mathrm{W}_{\mathrm{S}} \mathrm{B}$ digital measurements compared with visual severity, values of $r$ ranged from 0.67 to $0.91, \rho$ from 0.65 to $0.89, C_{b}$ from 0.93 to $0.98, v$ from 1.1 to 1.3 , and $u$ from 0.14 to 0.30 . And $\mathrm{W}_{\mathrm{S}} \mathrm{B}$ digital measurements compared with visual incidence showed values of $r$ that ranged from 0.64 to $0.89, \rho$ from 0.54 to $0.65, \mathrm{C}_{\mathrm{b}}$ from 0.71 to $0.84, v$ from 0.78 to 1.83 , and $u$ from 0.58 to 0.66 . Considering both locations, the proportion of nongreen vegetation pixels (1-gvp) yielded greater reliable and accurate values, especially when compared with visual $\mathrm{W}_{\mathrm{S}} \mathrm{B}$ severity estimations (Tables 5 and 6). Reliable $(0.96<r>0.83) \mathrm{W}_{\mathrm{S}} \mathrm{B}$ digital measurements using 1-gvp were observed starting at 55 DAI, when visual estimates of visual severity were 1 to 67 or 23 to $85 \%$, considering both locations (Figs. 4 and 5). $\mathrm{W}_{\mathrm{S}} \mathrm{B}$ digital measurements using 1-gvp consistently yielded accurate values $(0.92<\rho>$ 0.69 ) starting at $55 \mathrm{DAI}$ when compared with visual $\mathrm{W}_{\mathrm{S}} \mathrm{B}$ severity estimations and when the crop was at the Feekes stage 10.5.2 (flowering complete on top of head).

\section{DISCUSSION}

Based on associated disease cycle nature, there are two types of plant diseases: simple interest disease (SID) and compound interest disease (CID) (Pfender 1982; Vanderplank 1963). Therefore, plant diseases are classified by the lack (SID) or presence (CID) of pathogen spread from plant to plant (Madden et al. 2007; Vanderplank 1982). SID and CID are consequently biological models of disease progress which describe monocyclic and polycyclic diseases, respectively (Madden et al. 2007; Pfender 1982). The findings of this study demonstrate that the change of WB intensity in a susceptible host population over time does not consistently follow the pattern of a monocyclic disease.

First, $M$. oryzae Triticum is capable of infecting from vegetative stages of the host up to when wheat spikes have emerged, as reported by Cruz et al. (2015), Cruz and Valent (2017), and Martínez, et al. (2019). In this study, plants on inoculated plots received $M$. oryzae Triticum inoculum at the three-leaf stage, and leaf symptoms were initially reported prior to $\mathrm{W}_{\mathrm{S}} \mathrm{B}$ symptom development. Although $\mathrm{W}_{\mathrm{L}} \mathrm{B}$ severity was low during the vegetative stages, there was a clear bimodal shape when $\mathrm{W}_{\mathrm{L}} \mathrm{B}$ incidence DPCs were plotted, which might suggest the production of $M$. oryzae Triticum secondary inoculum and pathogen spread from plant to plant. The highest peaks of $\mathrm{W}_{\mathrm{L}} \mathrm{B}$ incidence were observed approximately 3 weeks after inoculation and around the earliest heading stage. Natural senescence of basal leaves (Cruz et al.2015) in combination with the development of $\mathrm{W}_{\mathrm{L}} \mathrm{B}$ symptoms in the middle canopy were responsible for that bimodal pattern. Bimodal disease progress curve patterns have been associated with polycyclic diseases, where plant organs are infected at different, separate times (Agrios 2005). Additionally, during heading, a continuous progress of $\mathrm{W}_{\mathrm{S}} \mathrm{B}$ symptoms ranged from near zero to maximum intensity in a period of 2.5 to 3 weeks.

Second, the shapes of the $\mathrm{W}_{\mathrm{S}} \mathrm{B}$ disease severity and incidence progress curves were appropriately described by the Gompertz model based on the selected criteria for model selection. Although Gompit transformation of $\mathrm{W}_{\mathrm{S}} \mathrm{B}$ disease severity and incidence (Gompertz model) showed better fit highlighted in the results section, one could use the logistic model for $\mathrm{W}_{\mathrm{S}} \mathrm{B}$ epidemics (Gomes et al. 2019) with no critical mistakes in understanding or making comparisons (Campbell and Madden 1990). Both Gompertz and logistic models have similar curve shapes and are often

TABLE 4. Summary of mixed-model analysis for the Gompertz transformations using full data-sets for locations in Bolivia (CEA-2 and CE-CAICO) ${ }^{\mathrm{a}}$

\begin{tabular}{llcllrl}
\hline Effect $^{\mathrm{b}}$ & Trt & Estimate & SE & DF & $t$ Value & $P r>|t|$ \\
\hline CEA-2 & & & & & & \\
$\quad$ Severity & & & & & & \\
$\quad$ Inoc & 0 & -6.2026 & 0.35 & 117 & -17.97 & $<0.0001$ \\
Inoc & 1 & -7.5662 & 0.35 & 117 & -21.75 & $<0.0001$ \\
DAI $\times$ Inoc & 0 & 0.09733 & 0.006 & 117 & 15.37 & $<0.0001$ \\
$\quad$ DAI $\times$ Inoc & 1 & 0.1396 & 0.006 & 117 & 22.05 & $<0.0001$ \\
Incidence & & & & & & \\
Inoc & 0 & -7.6250 & 0.78 & 117 & -9.80 & $<0.0001$ \\
Inoc & 1 & -10.1550 & 0.78 & 117 & -13.05 & $<0.0001$ \\
DAI $\times$ Inoc & 0 & 0.1343 & 0.02 & 117 & 9.11 & $<0.0001$ \\
DAI $\times$ Inoc & 1 & 0.2099 & 0.02 & 117 & 14.24 & $<0.0001$ \\
CE-CAICO & & & & & & \\
Severity & & & & & & \\
Inoc & 0 & -8.8614 & 1.45 & 116 & -6.10 & $<0.0001$ \\
Inoc & 1 & -16.2517 & 1.48 & 116 & -10.95 & $<0.0001$ \\
DAI $\times$ Inoc & 0 & 0.1723 & 0.03 & 116 & 5.60 & $<0.0001$ \\
DAI $\times$ Inoc & 1 & 0.3614 & 0.03 & 116 & 11.53 & $<0.0001$ \\
Incidence & & & & & & \\
Inoc & 0 & -10.4971 & 1.37 & 115 & -7.69 & $<0.0001$ \\
Inoc & 1 & -17.7679 & 1.43 & 115 & -12.44 & $<0.0001$ \\
DAI $\times$ Inoc & 0 & 0.2174 & 0.03 & 115 & 7.60 & $<0.0001$ \\
DAI $\times$ Inoc & 1 & 0.4115 & 0.03 & 115 & 13.83 & $<0.0001$ \\
\hline
\end{tabular}

${ }^{a}$ Models provided the slope (days after inoculation $[\mathrm{DAI}] \times$ inoculation [Inoc]) and intercept estimates for each inoculation treatment (Trt) $(0=$ noninoculated and $1=$ inoculated). $\mathrm{SE}=$ standard error.

${ }^{\mathrm{b}}$ Location, wheat spike blast intensity, and effect.

TABLE 3. Summary of mixed-model analysis for the Gompertz transformations using full data-sets for locations in Bolivia (CEA-2 and CE-CAICO)a

\begin{tabular}{|c|c|c|c|c|c|c|c|c|}
\hline \multirow[b]{2}{*}{ Intensity, effect ${ }^{\mathrm{b}}$} & \multicolumn{4}{|c|}{ CEA-2 } & \multicolumn{4}{|c|}{ CE-CAICO } \\
\hline & Num DF & Den DF & $F$ value & $\operatorname{Pr}>F$ & Num DF & Den DF & $F$ value & $\operatorname{Pr}>F$ \\
\hline \multicolumn{9}{|l|}{ Severity } \\
\hline Inoc & 1 & 117 & 7.86 & 0.0059 & 1 & 116 & 12.7 & 0.0005 \\
\hline DAI & 1 & 117 & 699.9 & $<0.0001$ & 1 & 116 & 147.7 & $<0.0001$ \\
\hline $\mathrm{DAI} \times \mathrm{Inoc}$ & 1 & 117 & 22.3 & $<0.0001$ & 1 & 116 & 18.53 & $<0.0001$ \\
\hline \multicolumn{9}{|l|}{ Incidence } \\
\hline Inoc & 1 & 117 & 5.47 & 0.0211 & 1 & 115 & 13.86 & 0.0003 \\
\hline DAI & 1 & 117 & 272.7 & $<0.0001$ & 1 & 115 & 232.2 & $<0.0001$ \\
\hline DAI $\times$ Inoc & 1 & 117 & 13.2 & 0.0004 & 1 & 115 & 22.1 & $<0.0001$ \\
\hline
\end{tabular}

${ }^{a}$ Models tested for equality of intercepts and slopes. Num $=$ numerator and Den $=$ denominator degrees of freedom (DF).

$\mathrm{b}$ Wheat spike blast intensity. Inoc $=$ inoculation and DAI $=$ days after inoculation. 


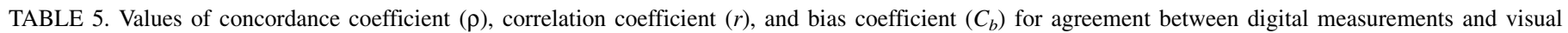
estimations (incidence or severity) of wheat spike blast at the CEA-2 location in Bolivia

\begin{tabular}{|c|c|c|c|c|c|c|}
\hline \multirow[b]{2}{*}{ Index, DAI ${ }^{\mathrm{a}}$} & \multicolumn{3}{|c|}{ Incidence } & \multicolumn{3}{|c|}{ Severity } \\
\hline & Accuracy $(\rho)$ & Precision $(r)$ & $\operatorname{Bias}\left(C_{b}\right)$ & Accuracy $(\rho)$ & Precision $(r)$ & Bias $\left(C_{b}\right)$ \\
\hline \multicolumn{7}{|l|}{ NDVI } \\
\hline 43 & 0.23 & 0.72 & 0.32 & 0.40 & 0.73 & 0.55 \\
\hline 47 & 0.16 & 0.70 & 0.23 & 0.16 & 0.70 & 0.23 \\
\hline 55 & 0.29 & 0.93 & 0.31 & 0.58 & 0.93 & 0.62 \\
\hline 57 & 0.20 & 0.90 & 0.22 & 0.20 & 0.90 & 0.22 \\
\hline 60 & 0.14 & 0.86 & 0.16 & 0.30 & 0.80 & 0.37 \\
\hline \multicolumn{7}{|l|}{ NDRE } \\
\hline 43 & 0.46 & 0.76 & 0.61 & 0.62 & 0.76 & 0.81 \\
\hline 47 & 0.35 & 0.75 & 0.46 & 0.80 & 0.84 & 0.94 \\
\hline 55 & 0.31 & 0.90 & 0.35 & 0.63 & 0.91 & 0.69 \\
\hline 57 & 0.20 & 0.86 & 0.23 & 0.48 & 0.86 & 0.56 \\
\hline 60 & 0.13 & 0.83 & 0.15 & 0.28 & 0.82 & 0.34 \\
\hline \multicolumn{7}{|l|}{ GNDVI } \\
\hline 43 & 0.24 & 0.70 & 0.34 & 0.41 & 0.70 & 0.58 \\
\hline 47 & 0.14 & 0.73 & 0.19 & 0.50 & 0.82 & 0.61 \\
\hline 55 & 0.16 & 0.92 & 0.17 & 0.33 & 0.92 & 0.36 \\
\hline 57 & 0.11 & 0.86 & 0.12 & 0.25 & 0.86 & 0.29 \\
\hline 60 & 0.07 & 0.85 & 0.08 & 0.05 & 0.14 & 0.33 \\
\hline \multicolumn{7}{|l|}{ GRVI } \\
\hline 43 & 0.53 & 0.67 & 0.79 & 0.36 & 0.67 & 0.54 \\
\hline 47 & 0.76 & 0.83 & 0.91 & 0.44 & 0.87 & 0.51 \\
\hline 55 & 0.44 & 0.90 & 0.49 & 0.81 & 0.92 & 0.88 \\
\hline 57 & 0.35 & 0.89 & 0.40 & 0.75 & 0.88 & 0.85 \\
\hline 60 & 0.00 & 0.14 & 0.02 & -0.02 & -0.28 & 0.08 \\
\hline \multicolumn{7}{|l|}{ OSAVI } \\
\hline 43 & 0.59 & 0.96 & 0.62 & 0.86 & 0.96 & 0.90 \\
\hline 47 & 0.61 & 0.86 & 0.71 & 0.77 & 0.91 & 0.85 \\
\hline 55 & 0.30 & 0.91 & 0.32 & 0.60 & 0.93 & 0.64 \\
\hline 57 & 0.24 & 0.88 & 0.27 & 0.55 & 0.87 & 0.63 \\
\hline 60 & -0.02 & -0.50 & 0.05 & -0.06 & -0.56 & 0.10 \\
\hline \multicolumn{7}{|l|}{ 1-gvp } \\
\hline 43 & 0.09 & 0.31 & 0.28 & 0.17 & 0.31 & 0.53 \\
\hline 47 & 0.11 & 0.57 & 0.20 & 0.4 & 0.66 & 0.61 \\
\hline 55 & 0.91 & 0.93 & 0.99 & 0.69 & 0.95 & 0.73 \\
\hline 57 & 0.90 & 0.94 & 0.96 & 0.71 & 0.95 & 0.74 \\
\hline 60 & 0.72 & 0.93 & 0.77 & 0.92 & 0.96 & 0.96 \\
\hline
\end{tabular}

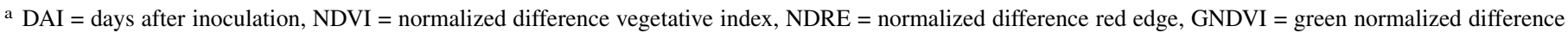
vegetative index, GRVI = green ratio vegetative index, OSAVI = optimized soil-adjusted vegetative index, and 1 -gvp $=$ nongreen vegetation pixels.

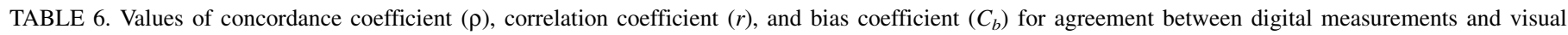
estimations (incidence or severity) of wheat spike blast at the CE-CAICO location in Bolivia

\begin{tabular}{|c|c|c|c|c|c|c|}
\hline \multirow[b]{2}{*}{ Index, $\mathrm{DAI}^{\mathrm{a}}$} & \multicolumn{3}{|c|}{ Incidence } & \multicolumn{3}{|c|}{ Severity } \\
\hline & Accuracy $(\rho)$ & Precision $(r)$ & Bias $\left(C_{b}\right)$ & Accuracy $(\rho)$ & Precision $(r)$ & Bias $\left(C_{b}\right)$ \\
\hline \multicolumn{7}{|l|}{ NDVI } \\
\hline 55 & 0.13 & 0.89 & 0.15 & 0.13 & 0.89 & 0.15 \\
\hline 58 & 0.13 & 0.86 & 0.15 & 0.25 & 0.90 & 0.28 \\
\hline \multicolumn{7}{|l|}{ NDRE } \\
\hline 45 & 0.24 & 0.67 & 0.35 & 0.50 & 0.67 & 0.74 \\
\hline \multicolumn{7}{|l|}{ GNDVI } \\
\hline 45 & 0.09 & 0.67 & 0.14 & 0.19 & 0.65 & 0.30 \\
\hline 55 & 0.06 & 0.88 & 0.06 & 0.15 & 0.84 & 0.18 \\
\hline 58 & 0.05 & 0.86 & 0.06 & 0.10 & 0.89 & 0.11 \\
\hline \multicolumn{7}{|l|}{ GRVI } \\
\hline 45 & 0.43 & 0.68 & 0.63 & 0.60 & 0.66 & 0.91 \\
\hline 55 & 0.16 & 0.85 & 0.19 & 0.42 & 0.77 & 0.54 \\
\hline \multicolumn{7}{|l|}{ 1-gvp } \\
\hline 45 & 0.54 & 0.64 & 0.84 & 0.65 & 0.67 & 0.96 \\
\hline 55 & 0.64 & 0.89 & 0.71 & 0.77 & 0.83 & 0.93 \\
\hline 58 & 0.65 & 0.87 & 0.74 & 0.89 & 0.91 & 0.98 \\
\hline
\end{tabular}

${ }^{a}$ DAI = days after inoculation, NDVI = normalized difference vegetative index, NDRE $=$ normalized difference red edge, GNDVI $=$ green normalized difference vegetative index, GRVI $=$ green ratio vegetative index, OSAVI $=$ optimized soil-adjusted vegetative index, and 1 -gvp $=$ nongreen vegetation pixels. 
used to describe and model polycyclic epidemics (Madden et al. 2007; Mouen Bedimo et al. 2007).

Third, autoinfection and allo-infections have been reported in a closely related and well-studied pathosystem, rice blast, for which the source of $M$. oryzae Oryza inoculum can originate from within rice fields or other nonrice hosts (Ashizawa et al. 2007; Teng et al. 1991). There is scientific evidence of the occurrence of M. oryzae Triticum autoinfection (Cruz et al. 2015), which is an infection
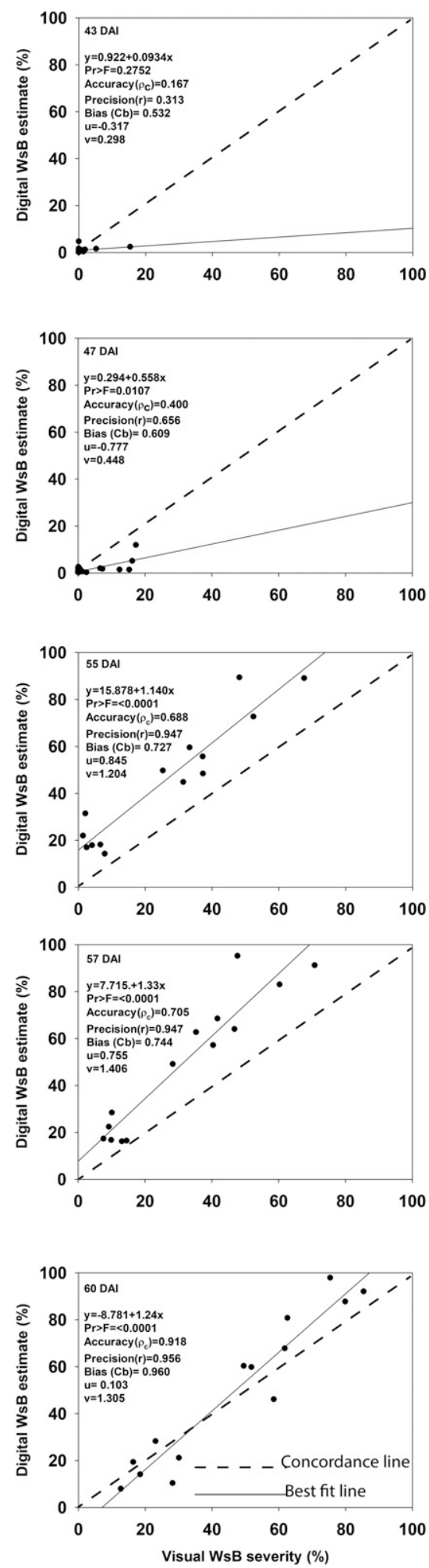

resulting from inoculum produced on the same wheat host unit. Autoinfection might occur from $M$. oryzae Triticum inoculum retained within the canopy to such a degree that self-infection increases among tissues. An unpublished study by coauthor J. D. Salgado and associates showed that M. oryzae Triticum inoculum and blast symptoms can spread from leaves to spikes, following a vertical movement. In addition, the possibility of $M$. oryzae Triticum infections resulting from allo-infection (e.g., inoculum
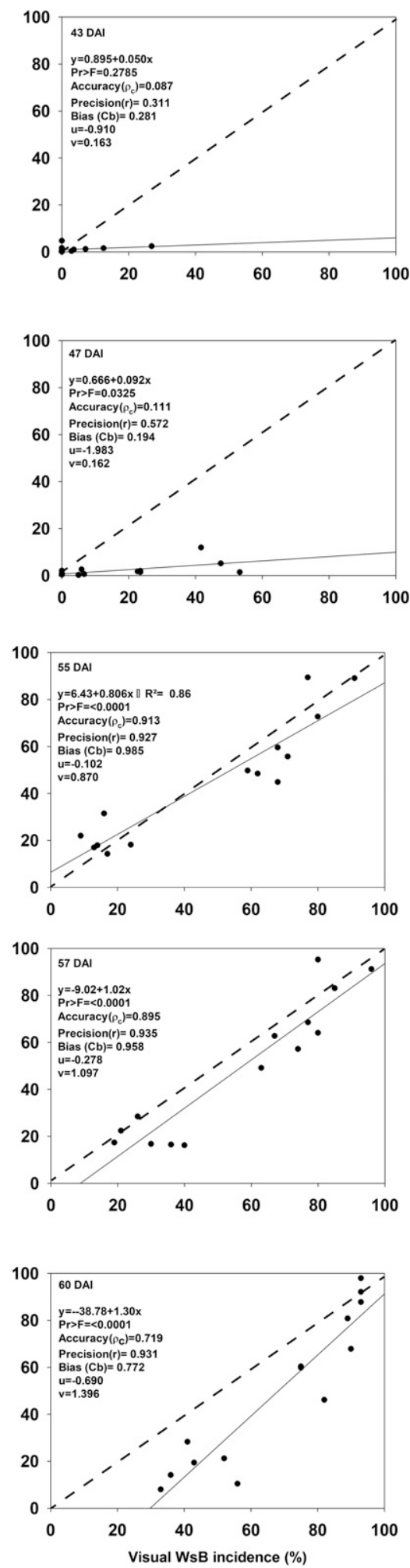

Fig. 4. Regression analysis of wheat spike blast $\left(\mathrm{W}_{\mathrm{S}} \mathrm{B}\right)$ visual disease assessment versus digital $\mathrm{W}_{\mathrm{S}} \mathrm{B}$ disease assessment. Graphs show accuracy $(\rho)$, precision $(r)$ bias $(\mathrm{Cb})$, scale shift $(v)$, and location shift $(u)$ for data collected at different days after Magnaporthe oryzae Triticum inoculation (DAI) at the CEA-2 location in Bolivia in $2017(n=16)$. 
produced on alternative host units) remains open (Fernandes et al. 2017) but more scientific research and evidence are needed. Our results do not discount the possibility that allo-infections may still be a major driver of epidemics.

From the data presented, however, it is not possible to rule out that an environment-host interaction had influenced the shapes of the disease progress curves, which were concluded to be an indication of secondary infection cycles. Environmental conditions, pathogen inoculum level and population structure, variation in host susceptibility, infection rate, and disease development over the course of the season (Pfender 1982) are critical to determine the full nature of WB disease epidemics. All of these factors need to be considered in future studies, because the amount of disease may be more subject to changes in environment and host susceptibility than is infection alone (Pfender 1982). Currently, there is an overall lack of knowledge of the M. oryzae Triticum population structure within wheat fields and the rate of disease increase over time under different varietal resistance levels. Most of the epidemiological evidence for the WB pathosystem includes results under limited environmental conditions and is based on one or few susceptible cultivars (Cruz et al. 2015; Gomes et al. 2019).
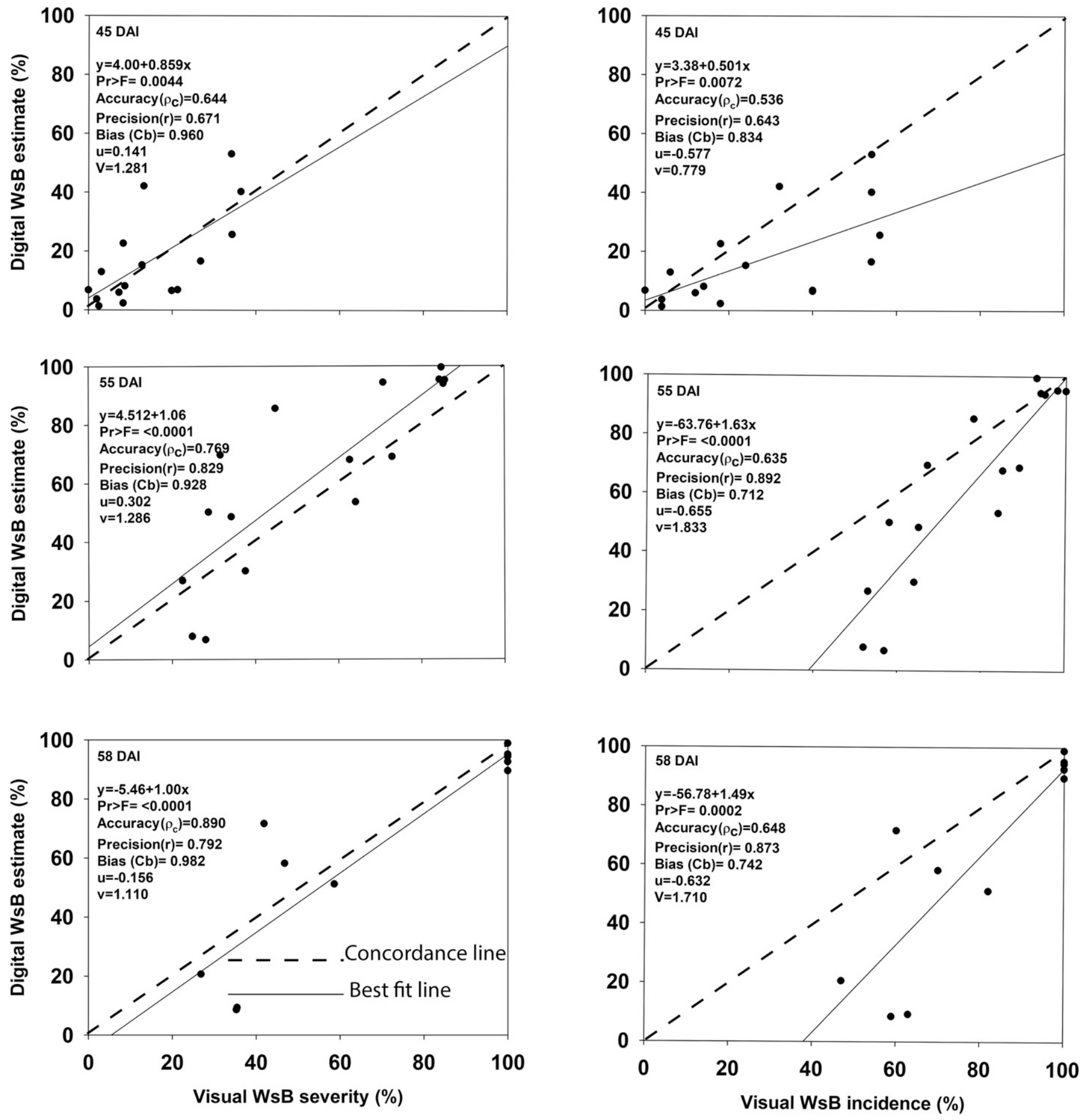

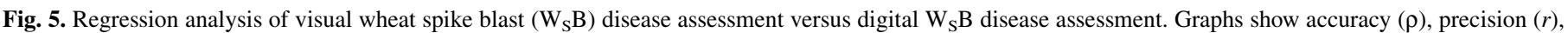

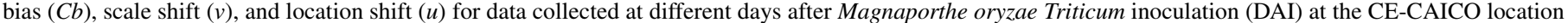
in Bolivia in $2017(n=16)$. 
Although VIs, in general, showed relatively high levels of precision at multiple time points, their accuracy values were generally low. The 1-gvp class yielded greater accuracy and precision values, especially when compared with visual $\mathrm{W}_{\mathrm{S}} \mathrm{B}$ severity estimations. These results are intuitive because calculations to obtain the nongreen pixel class included all five multispectral bands compared with VIs, which used more limited spectral information. Precise and accurate $\mathrm{W}_{\mathrm{S}} \mathrm{B}$ digital disease measurements were possible at moderately low-to-high visual $\mathrm{W}_{\mathrm{S}} \mathrm{B}$ severity levels, beginning at the wheat anthesis developmental stage. Although multispectral data are nonspecific for disease detection, it can be useful when additional stress factors are excluded by adequate management strategies (Heim et al. 2019). Our results open up a possibility of using digital disease measurement for $\mathrm{W}_{\mathrm{S}} \mathrm{B}$ plant disease resistance screening when sources of stress other than $\mathrm{W}_{\mathrm{S}} \mathrm{B}$ can be minimized. The deployment of spectral sensors through UAV sensing has the potential to increase the speed of $\mathrm{W}_{\mathrm{S}} \mathrm{B}$ screening and be a supplement to traditional methods of disease estimation. For those reasons, we propose the nongreen vegetation pixel classification as a proof-of-concept for dynamic $\mathrm{W}_{\mathrm{S}} \mathrm{B}$ detection under field conditions. However, there is room to improve this method, particularly during early symptom development, prior to anthesis. Lower precision and accuracy were observed prior to anthesis, especially when values of disease estimates and measurements were closer to zero. In such cases, it will be necessary to explore statistical approaches different than the one employed in this study (Lin et al. 2002) that are more appropriate for categorical variables (Madden et al. 2007). Moreover, higher-resolution imagery might increase the precision and accuracy of $\mathrm{W}_{\mathrm{S}} \mathrm{B}$ digital measurements.

Aerial imagery mostly covered upper plant organs such as spikes and upper leaves, and not lower plant organs. Challenges and limitations in field sensing of canopy surveillance include variations of illumination conditions that affect multiple canopy layers, structure of the canopy, and natural senescence of leaves (Mahlein et al. 2018). These challenges might have a direct impact on diseases of wheat leaves and spikes that develop from the lower to the upper canopy, becoming more severe as the season progresses (Mahlein et al. 2018). Considering that $\mathrm{W}_{\mathrm{L}} \mathrm{B}$ can occur prior to $\mathrm{W}_{\mathrm{S}} \mathrm{B}$ (Cruz et al. 2015), it would be necessary to develop adequate canopy surveillance methods (Mahlein et al. 2018) and determine whether imagery is capable of $\mathrm{W}_{\mathrm{L}} \mathrm{B}$ symptom detection at different canopy levels (Mahlein et al. 2018). Detection of other wheat diseases such as powdery mildew (Blumeria graminis) and leaf rust (Puccinia recondita) has been achieved; however, early detection was moderately suitable (Franke and Menz 2007). Due to the supervised nature of the image classification, the SCP procedure described here may have some user-introduced subjective bias. Therefore, classification procedures that require minimal manual intervention need to be explored further. Moreover, automated image classification procedures are highly desired from the scalability point of view, especially in field studies involving a large number of plots (Haghighattalab et al. 2016; Singh et al. 2019; Xavier et al. 2017). The temporal changes in the environmental conditions during the season may affect the accuracy of image classification. A robust image calibration pipeline can help minimize these classification issues. Future developments in sensors and data-processing methodologies are expected to improve the accuracy of the $\mathrm{W}_{\mathrm{S}} \mathrm{B}$ digital data.

Dependable and well-timed surveillance of WB occurrence and accurate estimates of disease intensity will continue to be important for crop quality assessment, breeding, and protection in general. Better phenotyping protocols should be developed to assess the rate of disease increase and as a tool to evaluate disease control strategies, and to facilitate local, regional, and worldwide communication of data and a faster response. $\mathrm{W}_{\mathrm{S}} \mathrm{B}$ signs and symptoms are quite distinct in the field and are often reported when wheat has reached the medium milk-to-dough growth stage (Cruz et al. 2016a). In spite of their prevalence on the lower canopy of susceptible and moderately resistant germplasm (Cruz and Valent 2017; Cruz et al. 2015), $W_{L} B$ symptoms are rarely reported because they are usually inconspicuous. $\mathrm{W}_{\mathrm{L}} \mathrm{B}$ appears to play a role in $\mathrm{W}_{\mathrm{S}} \mathrm{B}$ development. However, future research should consider doubly repeated measures analysis to fully evaluate the effects of treatment and repeated factors, and their interactions, when $\mathrm{W}_{\mathrm{L}} \mathrm{B}$ and $\mathrm{W}_{\mathrm{S}} \mathrm{B}$ measures are repeated in time and space. The aerial imagery collected in this study mainly captured the variation on healthy tissue on the upper canopy that, in most cases, was not affected by leaf blast (Cruz and Valent 2017; Cruz et al. 2015). Automated ground and aerial sensor-based methods must be explored to determine their potential for detection of $\mathrm{W}_{\mathrm{L}} \mathrm{B}$ and $\mathrm{W}_{\mathrm{S}} \mathrm{B}$. Future research should include the use of hyperspectral sensing, as well as the fusion of thermal with multispectral and hyperspectral data (Maes and Steppe 2019) to discriminate blast from other diseases during the early infection stages. In addition, a high-throughput framework based on computer vision and machine-learning algorithms that can detect and quantify $\mathrm{W}_{\mathrm{L}} \mathrm{B}$ and $\mathrm{W}_{\mathrm{S}} \mathrm{B}$ in RGB images and provide the spatial distribution of the disease will increase the chances of a faster response. These technological advances can provide a tool to maximize the efficiency of surveillance and crop protection strategies and lead to a paradigm shift in decision making regarding WB management.

\section{ACKNOWLEDGMENTS}

We thank Centro de Investigación Agrícola Tropical (CIAT), Cooperativa Agropecuaria Integral Colonias Okinawa (CAICO), and Asociación de Productores de Oleaginosas y Trigo (ANAPO) for support provided with the experiments conducted in Bolivia; M. G. Rivadeneira from CIAT for the help with import permits and inoculum preparation; D. F. Baldelomar, L. Calderón, J. Cuellar, and D. Coimbra from ANAPO for their help with field activities; G. Peterson for his contribution and commitment to the wheat blast work in South America; and L. V. Madden and P. Paul for their valuable help and guidance.

\section{LITERATURE CITED}

Agrios, G., ed. 2005. Plant Pathology, 5th ed. Academic Press, New York, NY U.S.A.

Albetis, J., Suthoit, S., Guttler, F., Jacquin, A., Goulard, M., Poilvé, H., Féret, J.-B., and Dedieu, G. 2017. Detection of Flavescence dorée grapevine disease using unmanned aerial vehicle (UAV) multispectral imagery. Remote Sens. 9:308.

Ashizawa, T., Sasahara, M., and Ohba, A., et al. 2007. Lesion-based analysis of leaf blast suppression in mixture of rice cultivar and resistant near-isogenic line. J. Gen. Plant Pathol. 73:15-21.

Barea, G., and Toledo, J. 1996. Pages 76-86 in: Identificación y zonificación de piricularia o bruzone (Pyricularia oryzae) en el cultivo del trigo en el dpto. de Santa Cruz. CIAT, Informe Técnico, Proyecto de Investigación Trigo, Santa Cruz, Bolivia.

Barnes, E. M., Clarke, T. R., and Richards, S. E. 2000. Coincident detection of crop water stress, nitrogen status and canopy density using ground based multispectral data. In: Proc. Fifth Int. Conf. Precis. Agric. P. C. Robert, R. H. Rust, and W. E. Larson, eds. American Society of Agronomy. Madison, WI, U.S.A.

Barnhart, H. X., Haber, M. J., and Lin, L. I. 2007. An overview on assessing agreement with continuous measurements. J. Biopharm. Stat. 17:529-569.

Bock, C. H., and Nutter, F. W., Jr. 2011. Detection and measurement of plant disease symptoms using visible-wavelength photography and image analysis. CAB Rev. Perspect. Agric. Vet. Sci. Nutr. Nat. Resour. 6:74-87.

Bock, C. H., Poole, G. H., Parker, P. E., and Gottwald, T. R. 2010. Plant disease severity estimated visually, by digital photography and image analysis, and by hyperspectral imaging. Crit. Rev. Plant Sci. 29:59-107.

Bowen, K. 2015. Models of disease progress. Pages 15-19 in: Exercises in Plant Disease Epidemiology, 2nd ed. K. Stevenson and M. Jeger, eds. American Phytopathological Society, St. Paul, MN, U.S.A.

Cabrera, M. G., and Gutiérrez, S. 2007. Primer registro de Pyricularia grisea en cultivos de trigo del NE de Argentina. In: Jornada de Actualización en Enfermedades de Trigo. IFSC Press, Lavallol, Buenos Aires, Argentina.

Calderón, R., Montes-Borrego, M., Landa, B. B., Navas-Cortés, J. A., and Zarco-Tejada, P. J. 2014. Detection of downy mildew of opium poppy using 
high-resolution multi-spectral and thermal imagery acquired with an unmanned aerial vehicle. Precis. Agric. 15:639-661.

Campbell, C. L., and Madden, L. V. 1990. Introduction to Plant Disease Epidemiology. John Wiley \& Sons, New York, NY, U.S.A.

Congedo, L. 2016. Semi-automatic classification plugin documentation, 5.3.2.1, 161-164. https://buildmedia.readthedocs.org/media/pdf/semi automaticclassificationmanual-v3/latest/semiautomaticclassificationmanualv3.pdf

Couture, J. J., Singh, A., Charkowski, A. O., Groves, R. L., Bethke, P. C., and Townsend, P. A. 2018. Integrating spectroscopy with potato disease management. Plant Dis. 102:2233-2240.

Cruz, C. D., Bockus, W. W., Stack, J. P., Tang, X., Valent, B., Pedley, K. F., and Peterson, G. L. 2012. Preliminary assessment of resistance among U.S. wheat cultivars to the Triticum pathotype of Magnaporthe oryzae. Plant Dis. 96:1501-1505

Cruz, C. D., Kiyuna, J., Bockus, W. W., Todd, T. C., Stack, J. P., and Valent, B. 2015. Magnaporthe oryzae conidia on basal wheat leaves as a potential source of wheat blast inoculum. Plant Pathol. 64:1491-1498.

Cruz, C. D., Peterson, G. L., Bockus, W. W., Kankanala, P., Dubcovsky, J., Jordan, K. W., Akhunov, E., Chumley, F., Baldelomar, F. D., and Valent, B. 2016a. The 2NS translocation from Aegilops ventricosa confers resistance to the Triticum pathotype of Magnaporthe oryzae. Crop Sci. 56: 990-1000.

Cruz, C. D., Santana, F. M., Todd, T. C., Maciel, J. L. N., Kiyuna, J., Baldelomar, D. F., Cruz, A. P., Lau, D., Seixas, C. S., Goulart, A. C. P., Sussel, A. A., Schipanski, C. A., Chagas, D. F., Coelho, M., Montecelli, T. D. N., Utiamada, C., Custódio, A. P., Rivadeneira, M. G., Bockus, W. W., and Valent, B. 2019. Multi-environment assessment of fungicide performance for managing wheat head blast (WHB) in Brazil and Bolivia. Trop. Plant Pathol. 44:183-191.

Cruz, C. D., and Valent, B. 2017. Wheat blast disease: Danger on the move. Trop. Plant Pathol. 42:210-222.

Cruz, M. F. A., Rios, J. A., Araujo, L., and Rodrigues, F. A. 2016b. Infection process of Pyricularia oryzae on the leaves of wheat seedlings. Trop. Plant Pathol. 41:123-127.

Dash, J. P., Watt, M. S., Pearse, G. D., Heaphy, M., and Dungey, H. S. 2017. Assessing very high-resolution UAV imagery for monitoring forest health during a simulated disease outbreak. ISPRS J. Photogramm. Remote Sens. 131:1-14.

Devanna, B. N., and Sharma, T. R. 2017. Wheat blast disease management: Cues from the advancements in molecular biology of rice-Magnaporthe pathosystem. J. Plant Biochem. Biotechnol. 27:249-259.

Everitt, B. S., and Skrondal, A. 2010. The Cambridge Dictionary of Statistics, 4th ed. Cambridge University Press, Cambridge, U.K.

Fernandes, J. M. C., Nicolau, M., Pavan, W., Holbig, C. A., Karrei, M., de Vargas, F., Bavaresco, J. L. B., Lazzaretti, A. T., and Tsukahara, R. Y. 2017. A weather-based model for predicting early season inoculum build-up and spike infection by the what blast pathogen. Trop. Plant Pathol. 42: 230-237.

Franke, J., and Menz, G. 2007. Multi-temporal wheat disease detection by multi-spectral remote sensing. Precis. Agric. 8:161-172.

Gitelson, A., and Merzlyak, M. 1998. Remote sensing of chlorophyll concentration in higher plant leaves. Adv. Space Res. 22:689-692.

Gomes, D. P., Rocha, V. S., Rocha, J. R. A. S. C., Souza, M. A., and Pereira, O. L. 2019. Progresso temporal da brusone do trigo em função do inóculo primário, da aplicação de fungicida e da resistência dos genótipos. Summa Phytopathol. 45:50-58.

Guan, J., and Nutter, F. W., Jr. 2001. Factors affecting the quality and quantity of sunlight reflected from alfalfa canopies. Plant Dis. 85:865-874.

Guan, J., and Nutter, F. W., Jr. 2004. Comparison of single-point alfalfa yield models based on visual disease intensity and remote sensing assessments. Can. J. Plant Pathol. 26:314-324.

Haghighattalab, A., González Pérez, L., Mondal, S., Singh, D., Schinstock, D., Rutkoski, J., Ortiz-Monasterio, I., Singh, R., Goodin, D., and Poland, J. 2016. Application of unmanned aerial systems for high throughput phenotyping of large wheat breeding nurseries. Plant Methods 12:35.

Heim, R. H. J., Wright, I. J., Scarth, P., Carnegie, A. J., Taylor, D., and Oldeland, J. 2019. Multispectral aerial disease detection for myrtle rust (Austropuccinia psidii) on a lemon myrtle plantation. Drones 3:25.

Igarashi, S., Utiamada, C. M., Igarashi, L. C., Kazuma, A. H., and Lopes, R. S. 1986. Pyricularia em trigo. 1. Ocorrência de Pyricularia sp. no estado do Paraná. Fitopatol. Bras. 11:351-352.

Inoue, Y., Peñuelas, J., Miyata, A., and Mano, M. 2008. Normalized difference spectral indices for estimating photosynthetic efficiency and capacity at a canopy scale derived from hyperspectral and $\mathrm{CO}_{2}$ flux measurements in rice. Remote Sens. Environ. 112:156-172.

Lin, L., Hedayat, S., Sinha, B., and Yang, M. 2002. Statistical methods in assessing agreement: Models, issues, and tools. J. Am. Stat. Assoc. 97: 257-270.
Lin, L. I.-K. 1989. A concordance correlation coefficient to evaluate reproducibility. Biometrics 45:255-268.

Madden, L. V., Hughes, G., and van den Bosch, F. 2007. The Study of Plant Disease Epidemics. American Phytopathological Society, St. Paul, MN, U.S.A.

Maes, W., and Steppe, K. 2019. Perspectives for remote sensing with unmanned aerial vehicles in precision agriculture. Trends Plant Sci. 24: $152-164$

Mahlein, A.-K. 2016. Plant disease detection by imaging sensors-Parallels and specific demands for precision agriculture and plant phenotyping. Plant Dis. 100:241-251.

Mahlein, A.-K., Kuska, M. T., Behmann, J., Polder, G., and Walter, A. 2018. Hyperspectral sensors and imaging technologies in phytopathology: State of the art. Annu. Rev. Phytopathol. 56:535-558.

Mahlein, A.-K., Rumpf, T., Welke, P., Dehne, H.-W., Plümer, L., Steiner, U., and Oerke, E. C. 2013. Development of spectral indices for detecting and identifying plant diseases. Remote Sens. Environ. 128:21-30.

Malaker, P. K., Barma, N. C. D., Tiwari, T. P., Collis, W. J., Duveiller, E., Singh, P. K., Joshi, A. K., Sigh, R. P., Braun, H. J., Peterson, G. L., Pedley, K. F., Farman, M. L., and Valent, B. 2016. First report of wheat blast caused by Magnaporthe oryzae pathotype Triticum in Bangladesh. Plant Dis. 100: 2330.

Martínez, S. I., Sanabria, A., Fleitas, M. C., Consolo, V. F., and Perello, A. 2019. Wheat blast: Aggressiveness of isolates of Pyricularia oryzae and effect on grain quality. J. King Saud. Univ. Sci. 31:150-157.

Mohanty, S. P., Hughes, D. P., and Salathé, M. 2016. Using deep learning for image-based plant disease detection. Front. Plant Sci. 7:1419.

Mouen Bedimo, J. A., Bieysse, D., Cilas, C., and Nottéghem, J. L. 2007. Spatio-temporal dynamics of arabica coffee berry disease caused by $\mathrm{Col}$ letotrichum kahawae on a plot scale. Plant Dis. 91:1229-1236.

Nita, M., Ellis, M. A., and Madden, L. V. 2003. Reliability and accuracy of visual estimation of Phomopsis leaf blight of strawberry. Phytopathol. 93: 995-1005.

Nutter, F. W., Jr., Esker, P. D., and Coelho Netto, R. A. 2006. Disease assessment concepts and the advancement concepts made in improving the accuracy and precision of plant disease data. Eur. J. Plant Pathol. 115:95-103.

Nutter, F. W., Jr., and Litwiller, D. 1993. Alfalfa Pro-A computerized disease assessment training program for foliar diseases of alfalfa. Page 15 in: Proc. 23rd Central Alfalfa Improve. Conf. University of Nebraska, Lincoln, NE, U.S.A.

Nutter, F. W., Jr., and Schultz, P. M. 1995. Improving the accuracy and precision of disease assessments: Selection of methods and use of computeraided training programs. Can. J. Plant Pathol. 17:174-184.

Nutter, F. W., Jr., Teng, P. S., and Shokes, F. M. 1991. Disease assessment terms and concepts. Plant Dis. 75:1187-1188.

Pfender, W. F. 1982. Monocyclic and polycyclic root diseases: Distinguishing between the nature of the disease cycle and the shape of the disease progress curve. Phytopathology 72:31-32.

QGIS Development Team. 2017. QGIS Geographic Information System. Open Source Geospatial Foundation Project 2014. https://qgis.org

Rahaman, M. M., Chen, D., Gillani, Z., Klukas, C., and Chen, M. 2015. Advanced phenotyping and phenotype data analysis for the study of plant growth and development. Front. Plant Sci. 6:619.

ReliefWeb. 2017. South America: Drought 2015-2017. https://reliefweb.int/ disaster/dr-2016-000002-col

Renner-Martin, K., Kühleitner, M., Brunner, N., and Hagmüller, W. 2016. AIC-based selection of growth models: The case of piglets from organic farming. Open J. Model. Simul. 4:17-23.

Rondeaux, G., Steven, M., and Baret, F. 1996. Optimization of soil adjusted vegetation indices. Remote Sens. Environ. 55:95-107.

Rouse, J. W., Jr., Haas, R. H., Schell, J. A., Deering, D. W., and Harlan, J. C. 1974. Monitoring the Vernal Advancement and Retrogradation (Greenwave Effect) of Natural Vegetation. Prog. Rep. RSC 1978-1. Remote Sensing Center, Texas A\&M University, College Station, TX, U.S.A. https:// ntrs.nasa.gov/archive/nasa/casi.ntrs.nasa.gov/19750020419.pdf

Singh, D., Wang, X., Kumar, U., Gao, L., Noor, M., Imtiaz, M., Singh, R. P., and Poland, J. 2019. High-throughput phenotyping enabled genetic dissection of crop lodging in wheat. Front. Plant Sci. 10:394.

Sripada, R. P., Heiniger, R. W., White, J. G., and Meijer, A. D. 2006. Aerial color infrared photography for determining early in-season nitrogen requirements in corn. Agron. J. 98:968-977.

Teng, P., Klein-Gebbinck, H., and Pinnschmidt, H. 1991. An analysis of the blast pathosystem to guide modeling and forecasting. Pages 1-30 in: Rice Blast Modeling and Forecasting-Selected Pap. Int. Rice Res. Conf. International Rice Research Institute, Manila, Philippines.

Toledo, J. 2015. Fungicidas para tratamiento de semillas de trigo. Pages 47-56 in: Manual de recomendaciones técnicas cultivo de trigo 2015. Asociación de Productores de Oleaginosas y Trigo ANAPO, eds. Santa Cruz de la Sierra, Bolivia. 
Valent, B., Farral, L., and Chumley, F. G. 1991. Magnaporthe grisea genes for pathogenicity and virulence identified through a series of backcrosses. Genetics 127:87-101.

Vanderplank, J. E. 1963. Plant Diseases: Epidemics and Control. Academic Press, New York, NY, U.S.A

Vanderplank, J. E. 1982. Host-Pathogen Interaction in Plant Disease. Academic Press, London.

Viedma, L. Q. 2005. Wheat blast occurrence in Paraguay. (Abstr.) Phytopathology 95:S152.

Weiss, K. R. 2018. Some of the World's Biggest Lakes Are Drying Up. Here's Why. National Geographic Magazine. https://www.nationalgeographic.com/ magazine/2018/03/drying-lakes-climate-change-global-warming-drought/

West, J. S., Bravo, C., Oberti, R., Lemaire, D., Moshou, D., and McCartney, H. A. 2003. The potential of optical canopy measurement for targeted control of field crop diseases. Annu. Rev. Phytopathol. 41:593-614.
West, J. S., Bravo, C., Oberti, R., Moshou, D., Ramon, H., and McCartney, H. A. 2010. Detection of fungal diseases optically and pathogen inoculum by air sampling. Pages 135-149 in: Precision Crop Protection-The Challenge and Use of Heterogeneity. E.-C. Oerke, R. Gerhards, G. Menz, and R. A. Sikora, eds. Springer, Dordrecht, The Netherlands.

Xavier, A., Hall, B., Hearst, A., Cherkauer, K., and Rainey, K. 2017. Genetic architecture of phenomic-enabled canopy coverage in Glycine max. Genetics 206:1081-1089.

Zarco-Tejada, P. J., Camino, C., Beck, P. S. A., Calderon, R., Hornero, A., Hernández-Clemente, R., Kattenborn, T., Montes-Borrego, M., Susca, L., Morelli, M., Gonzalez-Dugo, V., North, P. R. J., Landa, B. B., Boscia, D., Saponari, M., and Navas-Cortes, J. A. 2018. Previsual symptoms of Xylella fastidiosa infection revealed in spectral plant-trait alterations. Nat. Plants 4:432-439.

Zhang, C., and Kovacs, J. M. 2012. The application of small unmanned aerial systems for precision agriculture: A review. Precis. Agric. 13:693-712. 